\title{
Stokastik Çok Kriterli Kabul Edilebilirlik Analizi ile Bir Kamu Kurumu için Tesis Yeri Seçimi
}

\author{
Facility Location Selection for a Public Organization by Stochastic Multi-criteria \\ Acceptability Analysis
}

\author{
Selahattin KARABAY ${ }^{1}$,Erkan KÖSE ${ }^{2}$, Mehmet KABAK ${ }^{3}$
}

\begin{abstract}
ÖZET
Tesis yeri seçimi, özellikle son 50 yıldır birçok çalışmanın yapıldığı bir problem sahasıdır. Hızla gelişen teknoloji, çevresel etkenler, rekabet için işletme maliyetlerinin azaltılması gerekliliği, müşterilerin memnuniyet algılarındaki değişim gibi birçok faktör bu problemler için bilimsel yöntemler kullanılarak maliyet etkin çözümler bulunmasını gerektirmektedir. Bu çalışmada, bir kamu kurumuna ait tesis yeri seçimi problemi için çözüm önerilmiştir. Problem, temel olarak kamu kurumunun ülke genelinde il ve ilçelerde konuşlu hizmet merkezi sayısını azaltmak istemesinden kaynaklanmaktadır. Mevcut tesisler kamu kurumunun genel yönetimi tarafından belirlenen kriterlere göre değerlendirilmiş, açık tutulması gerekenler ve kapatılması gerekenler olarak iki sınıfa ayrılmışıtır. Çalışmada yöntem olarak Stokastik Çok Kriterli Kabul Edilebilirlik AnaliziTRI (SMAA-TRI) kullanılmıştır.
\end{abstract}

Anahtar Kelimeler: Tesis yeri seçimi, ÇKKV, SMAA

\begin{abstract}
The facility location problem, especially in the last 50 years, is an area where too many studies occur. Rapidly evolving technology, environmental factors, the necessity to reduce operation costs required to compete and many factors such as changes in customer perception of satisfaction force cost effective solutions by using scientific methods for these problems. In this study, a real life public sector facility location problem is examined. The problem fundamentally originated from the desire of public sector to downsize the number of service centers stationed in various cities and towns countrywide. Existing facilities are sorted in two groups as facilities which stay opened and facilities which should be closed according to criteria determined by general management. In the study Stochastic Multi-Criteria Acceptability Analysis-TRI (SMAA-TRI) is used as the method.
\end{abstract}

Keywords: Facility location selection, MCDM, SMAA

Yöneylem araştırmasının iki ana dalı, tesis yeri seçimi problemleri için etkin çözüm yolları sunmaktadır. Bunların birincisi; matematiksel modellemedir. Tesis yeri seçimi için oluşturulan matematiksel modeller, tesislerin nerelere kurulacaklarını ve hangi müşterilerin hangi tesislerden hizmet ya da ürün alacaklarını tespit eder. Tesis yeri seçimi problemlerinin çözümünde yaygın olarak kullanılan diğer bir yaklaşım; Çok Kriterli Karar Verme (ÇKKV) yöntemleridir. ÇKKV yöntemleri, genellikle çeşitli ölçütlere dayanarak aday yerlerden hangisi ya da hangilerine tesis kurulması gerektiğini ortaya koyar.

ÇKKV problemlerinde, kararın niteliği büyük ölçüde karar vericilerden sağlanan kriter ağırlıkları ve alternatiflerin kriterlere göre aldıkları değerlerin doğru bir şekilde belirlenmesine bağlıdır. Gerçek hayat problemlerinde, bu değerlerin tümüne doğru şekilde ulaşmak çoğu zaman mümkün değildir. Politik ve kamusal problemlerde, karar vericilerin birden çok olduğu, verilerin büyük ölçüde değişkenlik gösterdiği

\footnotetext{
' Dr., Kara Harp Okulu, Savunma Bilimleri Enstitüsü, Yöneylem Araştırması Ana Bilim Dalı, selahattin_karabay@hotmail.com

${ }^{2}$ Dr., Kara Harp Okulu, Savunma Bilimleri Enstitüsü, Harekat Araştırması Bölümü, erkankose93@gmail.com

${ }^{3}$ Dr., Kara Harp Okulu, Savunma Bilimleri Enstitüsü, Harekat Araştırması Bölümü, mkabak@kho.edu.tr
} 
durumlarda, söz konusu değerlerin doğru bir şekilde belirlenmesi daha da karmaşık bir hâl almaktadır.

Stokastik Çok Kriterli Kabul Edilebilirlik Analizi (SMAA) yöntemi, alternatiflerin kriter değerlerinin ve kriter ağılıklarının politik ve benzeri nedenlerle karar vericilerden temin edilemediği, eksik veya belirsiz olduğu ÇKKV problemlerinin çözümü için geliştirilmiştir (Tervonen ve Lahdelma, 2007).

Bu çalışmada, bir kamu kurumuna ait gerçek bir tesis yeri seçimi problemi ele alınmıştır. Problem, temel olarak kamu kurumunun ülke çapında çeşitli il ve ilçelerde konuşlu hizmet merkezi sayısını azaltmak istemesinden kaynaklanmaktadır. Kamu kurumunun bir hizmet merkezinin sahip olmasını istediği niteliklerden en fazlasına sahip olanlar SMAA-TRI yöntemi ile mevcut tesisler arasından tespit edilmiştir. Sistemde mevcut olan hizmet birimleri, genel yönetim tarafından belirlenen altı kritere göre SMAA-TRI ile değerlendirilmiştir. Yapılan sınıflandırma ile mevcut hizmet birimleri, kapatılması ve açık bulundurulması gereken tesisler şeklinde iki kategoriye ayrılmıştır.

\section{LITERATÜR ARAŞTIRMASI}

Tesis yeri seçimi problemleri için ÇKKV metotlarının kullanılmasına dair literatürde yer alan dikkat çekici çalışmalardan biri Kahraman vd. (2003)'nin çaıışmasıdır. Araştırmacılar, tesis yeri seçim problemleri için içerisinde bulanık Analitik Hiyerarşi Yönteminin de (AHP) bulunduğu dört farklı bulanık ÇKKV metodunu analiz etmiştir (Kahraman vd., 2003). Diğer metotlar sırası ile Blin tarafından önerilen bulanık model grup karar verme, bulanık sentetik değerlendirme ve Yeger'in ağırlıklandırılmış hedefler metodudur (Blin, 1974). Başka bir çalışmada, uluslararası turistik otel yerlerinin seçimi için 21 kriterin kullanıldığı bulanık ÇKKV yöntemleri önerilmiştir. Yazarlar, değerlendirmede kullanılan 21 kriterin ağırlıklandırılması için dört farklı yöntem kullanmıştır. Bu yöntemler; bulanık küme teorisi, dilbilimsel değerler, hiyerarşik yapı analizi ve bulanık AHP yöntemleridir (Chou vd., 2008). Bulanık AHP yöntemi 2009 yılında tersane yeri seçimi problemi için kullanılmıştır. Değerlendirilen dört alternatiften (İzmir, Yalova, Yumurtalık ve Samsun) Yalova en uygun tersane yeri olarak seçilmiştir (Güneri vd., 2009). Londra'da yapılacak bir gazino için alternatif yerlerin değerlendirilmesi ÇKKV yöntemlerinden TOPSIS ve PROMETHEE kullanılarak yapılmıştır. Araştırmacılar kârlılık ve sosyal fayda sağlama açılarından probleme yaklaşmış, ayrıca çözümde ağırlıklı toplam yöntemini de kullanmışlardır (Ishizaka vd., 2013).

Literatürde tesis yeri seçimi problemlerinin çözümü için birden fazla yöntemin bütünleşik olarak kullanıldığı çalışmalar da mevcuttur. Badri (1999), hedef programlama ve AHP metodunu birleştirerek tesis yeri seçim problemleri için yeni bir model önermiştir. Çalışmada, uluslar arası bir petrokimya şirketinin kuracağı dağıtım üssü için Suudi Arabistan, Birleşik Arap Emirlikleri, Bahreyn, Kuveyt, Katar ve Umman incelenmiştir. Alternatifler; politik durum, küresel rekabet potansiyeli, hükümet kuralları ve ekonomiklik kriterlerine göre değerlendirilmiştir. Uygulamada ilk önce AHP ve hedef programlama tek tek kullanılmış, daha sonra bütünleşik yöntem kullanılarak sonuçlar karşılaştırılmıştır. Vahidnia vd. (2009) coğrafi bilgi sistemleri ve bulanık AHP metodunu birleştirerek Tahran'da inşa edilecek bir hastane için yer seçimi problemine çözüm sunmuşlardır. Farahani vd. (2010) çalışmaların$\mathrm{da}$, tesis yeri seçimi problemleri için kullanılan ÇKKV yöntemlerini; iki amaçlı, çok amaçlı ve çok nitelikli olarak üç kategoriye ayırarak incelemiştir.

ÇKKV yöntemlerini gerçek hayat problemlerine yaklaştırmak için eksik veya belirsiz bilgi içeren çeşitli metotlar geliştirilmiştir. Bu alanda uzun yıllar çalışmalar yapılmasına rağmen, hem alternatiflerin kriter değerleri hem de kriter ağırlıklarının stokastik değişkenler olarak ifade edilebildiği ilk yöntem SMAA yöntemidir (Tervonen ve Lahdelma, 2007).

SMAA metodu, Helsinki'de liman yeri seçimi probleminin çözümü ile bağlantılı olarak önerilmiştir. Çalışmada, Helsinki liman inşası için 24 alternatif arasından 11 kritere göre en uygun olan belirlenmiştir (Hokkanen vd., 1999; Tervonen ve Figueira, 2008). Bu çalışma, SMAA metodunun kullanıldığı ilk gerçek yaşam problemi ve SMAA metodunun kullanıldığı ilk tesis yeri seçimi problemi olarak göze çarpmaktadır. Bundan sonra birçok gerçek yaşam problemin çözümü için değişik SMAA metotları önerilmiştir. Lahdelma vd. (2002), sıralı kriter değerlerine sahip alternatifler için sundukları yeni bir SMAA metodu olan SMAA-O metodu ile Finlandiya'da bir atık arıtma tesisinin yerini seçmişlerdir. Bu çalışmada yazarlar, dört alternatifi 17 kritere göre değerlenmiştir. SMAA-O, Fas'a yapılacak bir havaalanı ana dağıtım üssü için 9 alternatifin değerlendirilmesinde de kullanılmıştır (Menou vd., 2010). Yazarlar alternatifleri, yatırım maliyeti, üreticilere yakınlık, bölge potansiyeli, ulaştırma maliyeti, servis seviyesi ve çevre olmak üzere altı kritere göre değerlendirmiş̧tir.

Literatürdeki çalışmalar incelendiğinde, tesis yeri seçimi problemi için yapılan çalışmalarda iki yaklaşım göze çarpmaktadır: Girdi verilerinin stokastik/olasılıkIı ya da kesin olmayan değerler şeklinde ele alındığı yöntemler kullanmak veya birden fazla yöntemin bütünleşik olarak kullanılması. Bu çalışmada, gerçek bir yaşam probleminin çözümünde SMAA-TRI metodu kullanılmıştır. Bu çalışma, literatürdeki diğer çalışmalardan iki şekilde farklıdır: 
- SMAA-TRI metodu ilk defa tesis yeri seçimi probleminde kullanılmıştır.

- SMAA metodunu kullanan tesis yeri seçimi problemlerinde tesis sayısı bir iken bu çalışmada tesis sayısı birden fazladır.

\section{STOKASTIK ÇOK KRITERLI KABUL EDILEBiLIRLIKK ANALIZi}

Gerçek yaşam problemleri için geliştirilmiş birçok ÇKKV metodu bulunmaktadır. Bunların en eski olanlarından bir tanesi fayda fonksiyonudur. Bu metotla ilgili ayrıntılı bilgi ve uygulamalar Figueira vd. (2005)'nin yaptığı çalışmada mevcuttur. Fayda fonksiyonu metodu, problemin çözümü için kesin parametre değerlerine ihtiyaç duymaktadır. Gerçek hayatta kesin değerlere ulaşmak her zaman mümkün değildir. Bunun üstesinden gelmek için ters ağırlık uzayı yaklaşımı kullanılmıştır. Ters ağırlık uzayı yaklaşımı; problemi çözmek için parametre değerlerini sormak yerine farklı alternatiflerin hangi parametre değerleri ile seçilebileceğine cevap aramaktadır.

SMAA ters ağırlık uzayı hesaplamalarını çok boyutlu integrallerle gerçekleştirmektedir. İntegral hesaplamalarını yaparken kullandığı yöntemlerden birisi Monte Carlo Simülasyonudur. SMAA'dan önce ters ağırlık uzayı mantığına dayanan başka ÇKKV metotları da kullanılmıştır (Tervonen ve Figueira, 2008). SMAA metodu için temel teşkil eden iki yöntem bulunmaktadır:

- Kıyaslamalı yüksek hacim kriteri metodu

- Kapsamlı uzlaşma kriteri metodu

Kıyaslamalı yüksek hacim kriteri metodu, her bir alternatifi en çok tercih edilen alternatif yapacak çok boyutlu ağırık kümesi hesaplamasına dayanır. Bu yöntem, kriterlerin ağırlık değerlerini doğrusal kısıtlar şeklinde ele alır. Fakat, alternatiflerin kriter değerleri deterministiktir ve ilave fayda fonksiyonları ile sınırlandırılmıştır (Tervonen ve Figueira, 2008).

Kapsamlı uzlaşma kriteri, 1986 yılında Bana e Costa tarafından ortaya koyulmuştur (Tervonen ve Figueira, 2008). Bu metotta, karar vericilerin tercihleri arasındaki çatışmaların hesaplanması üzerinde durulmuştur. Yöntemin en önemli eksikliği sadece üç kriter kullanılabiliyor olmasıdır. Bu nedenle, yöntem gerçek hayat problemlerini yansıtmada yetersiz kalmaktadır.

SMAA metodu, alternatiflerin kriter değerlerinin ve kriter ağırlıklarının kesin olarak bilinemediği durumlar için geliştirilmiştir. Belirsiz veya kesin olmayan alternatiflerin kriter değerleri, stokastik değişkenler ile temsil edilirler. Aynı şekilde karar vericilerin üzerinde uzlaşamadığı kriterlerin ağırlıkları da birleşik yoğunluk fonksiyonlu ağırlık dağılımı ile temsil edilir. SMAA metodunun gerçek hayat problemlerine uygun olmasının nedenlerini Tervonen ve Lahdelma (2007), şu şekilde belirtmişlerdir.

- SMAA metodunun kullandığı ters ağırlık uzayı yaklaşımı, karar vericilerden alternatiflerin kriter değerlerinin sağlanamadığı problemler için uygun bir yaklaşımdır. Böyle durumlarda, alternatiflerin kriter değerleri bir aralık veya üzerinde uzlaşılan bir istatistiksel dağılımla ifade edilebilir.

- SMAA metodu, eksik veya belirsiz kriter ağırlıklarının yer aldığı problemlerin çözümü için uygun bir yöntemdir.

- SMAA hesaplamaları, sayısal metotlarla etkin olarak gerçekleştirilebilmektedir.

SMAA yöntemi, ortaya atıldığı ilk günden bu güne kadar farklı tipteki problemlere çözümler bulabilmek için gelişme kaydetmiş ve SMAA-2 (Lahdelma ve Salminen, 2001), SMAA-3 (Hokkanen, 1998), SMAA-O (Lahdelma vd., 2003), Ref-SMAA (Lahdelma vd., 2005) ve SMAA-TRI (Tervonen vd., 2009) yöntemleri ortaya konmuştur.

\subsection{SMAA-TRI Yöntemi}

2009 yılına kadar geliştirilen SMAA metotlarının tümü seçim ve sıralama problemleri içindir. SMAA-TRI metodu, Tervonen vd. (2009) tarafından sınıflandırma problemlerinin çözümü için geliştirilmiştir. Bu metot, ELECTRE-TRI metodunun kriter değerleri ve kriter ağırlık değerlerinde belirsizliğe izin verecek şekilde geliştirilmesi ile ortaya çıkmıştır (Yu, 1992).

ELECTRE-TRI, alternatifleri önceden belirlenmiş ve sıralanmış kategorilere göre sınıflandırmak için uyumluluk ve uyumsuzluk indislerini kullanır. Artan tercih sırasına göre kategoriler şu şekilde gösterilebilir: , $C_{k}$ en iyi kategoridir. Bu kategoriler, her kriter için ölçümleri içeren alt ve üst profiller ile tanımlanır. Atama prosedüründe alternatifler, teker-teker profiller ile kıyaslanır. Profiller, $p_{1^{\prime}} \ldots, p_{h^{\prime}, \ldots,} p_{k-l^{\prime}}$ ile simgelenir. $P_{h^{\prime}} C_{h}$ kategorisinin üst limiti ve $C_{h+1}$ kategorisinin alt limitidir. Profiller, aşağıdaki ilişkiyi karşılayacak şekilde tam olarak sıralı olmalıdır $\left(p_{1} \Delta p_{2}, p_{2}\right.$ 'nin $p_{1}$ 'e baskın olduğu anlamına gelir):

$$
p_{1} \Delta p_{2} \Delta \ldots p_{k-2} \Delta p_{k-1}
$$

Bu baskınlık ilişkisi dikkatli yorumlanmalıdır; çünkü baskınlık sadece iki profilin bileşenlerinin değerine değil; aynı zamanda eşik değerlerine de bağlıdır. Atama süreci, ilave teknik bir parametreye, lambda kesme seviyesine $(\lambda)$ ihtiyaç duyar (Tervonen ve Figueira, 2008). 
SMAA-TRI metodu, ELECTRE-TRI metodundan aşağıdakileri girdi olarak kullanır:

1. Lambda kesme seviyesi, [0,5 1$]$ aralığında $f_{L}(\lambda)$ yoğunluk fonksiyonuna sahip $\lambda$ stokastik değişkeni ile tanımlanır.

2. Alternatiflerin kriter değerleri ve kriter ağırlıkları eksik, aralıklı bir değer olarak ya da bir dağıım fonksiyonuna uygun olarak girilebilir.

3. Ağırlıklar, W uygun ağırlık uzayında $f_{w}(w)$ birleşik yoğunluk fonksiyonlu bir ağırlık dağılımıyla tanımlanır. Toplam kriter ağırlıkları bilgisi eksikliği W'deki düzgün kriter ağırlık dağılımı $f_{w}(w)=1 / v o l(W)$ ile gösterilir. Ağırlıklar sıfır veya sıfırdan büyük ve normalize edilmiş̧ir. Ağırlık uzayı $n$ boyutlu uzayda $(n-1)$ boyutlu bir simplekstir.

$$
W=\left\{\omega \in R^{n}: \omega \geq 0 \text { ve } \sum_{j} \omega_{j}=1\right\}
$$

4. ELECTRE-TRI'ye ait veri ve diğer parametreler, $T$ $=\{M, B, q, p, v\}$ kümesi ile gösterilir. $M$, kriter değerlendirme matrisi, $B$ ise profil kümesidir. Problemi basitleştirme amaçlı bu bileşenlerin deterministik değerler olduğu kabul edilmektedir.

SMAA-TRI tüm alternatifler ve kategoriler için kategori kabul edilebilirlik indisleri $\left(\pi_{\mathrm{i}}^{h}\right)$ üretir. Kategori kabul edilebilirlik indisleri, alternatiflerin $\left(a_{i}\right)$, kategorilere $\left(C_{h}\right)$ yüzde olarak hangi oranda uyum sağladığını gösterir. Alternatiflerin ELECTRE-TRI tarafından kategori indisi $h$ 'ye atanmasını değerlendiren kategorileştirme fonksiyonu şöyledir.

$$
h=K(i, \Lambda, W, T)
$$

Kategori üyelik fonksiyonu aşağıdaki şekilde tanımlanır.

$$
m(, w, t) \quad\left\{\begin{array}{l}
1, \text { eger } K(i, \Lambda, w, T)=h \\
0, \text { diger durumlarda. }
\end{array}\right.
$$

SMAA-TRI metodunda kategori kabul edilebilirlik indisi, çoklu integraller ile aşağıdaki şekilde hesaplanır.

$$
\pi_{\mathrm{i}}^{h}=\int_{0}^{1} f_{L}(\Lambda) \int_{\omega \in W} f_{\omega}(\omega) \mathrm{m}_{i}^{h}(\Lambda, \mathrm{w}, \mathrm{T}) d \omega d \Lambda
$$

Kategori kabul edilebilirlik indisleri 0 ile 1 aralığındadır. Sıfır değeri, alternatifin o kategoriye atanma olasılığının olmadığını, 1 ise alternatifin kesinlikle o kategoriye ait olduğunu gösterir. Her alternatifin, tüm kategoriler için kategori kabul edilebilirlik indisleri toplamı 1'dir. Kategori kabul edilebilirlik indisleri, Monte Carlo Simülasyonu kullanılarak hesaplanabilir.
ELECTRE-TRI, alternatifin hangi kategorilere ait olabileceğine dair bir bilgi sağlarken, SMAA-TRI, alternatifin hangi oranda hangi kategoriye ait olabileceği bilgisini verir. Bu ilave bilginin sağladığı üç avantaj şöyledir.

- Duyarlılık analizinde, parametrelerin uç noktalarının belirlenmesi için ihtiyaç duyulan çaba azaltılmıştır. Böylece uzayın, örnek olarak düzgün dağılımlı olmasına karar verilmiş ve aralıktaki küçük değişikliklerin, sonucu büyük oranda değiştirmemesi sağlanmıştır.

- Durağan olmayan atamalarla sonuçlanan parametre değerlerinin miktarının sayısallaştırılması, kesin olmayan parametrelerle ilgili riski belirler.

- Kriter ağırlıkları belirleme teknikleri, farklı ağırlık değerleri sağlar. Böylece, ağırlıkları deterministik değerler yerine, kesin olmayan değerler şeklinde belirlemek daha uygun görünmektedir.

SMAA metodunda hesaplamaların elle yapılması, özellikle büyük boyutlu problemlerde kolay değildir. Yukarıda metodun teorik altyapısı anlatılmaktadır, problemlerin çözümlerinde ise JAVA tabanlı açık kaynak yazııımı JSMAA kullanılmaktadır.

\section{UYGULAMA}

Bu çalışmada, bir kamu kurumuna ait gerçek bir tesis yeri seçimi problemi ele alınmıştır. Bu problem, temel olarak kamu kurumunun ülke çapında çeşitli il ve ilçelerde konuşlu hizmet merkezi sayısını azaltmak istemesinden kaynaklanmaktadır.

Kamu kurumu, ülkeyi 20 bölgeye ayırmış ve bölgelerin başına birer bölge başkanlığı tahsis etmiştir. Kurum, ülke genelinde tesis sayısını azaltmak ve maliyet etkin bir yapıya getirmek istemektedir. Çalışmada, ülkenin tamamı yerine kurum yönetiminin belirlediği bir bölgede uygulama gerçekleştirilmiştir. Çalışmada, tek bir bölgenin ele alınmış olması problemin geneli için herhangi bir sorun teşkil etmemektedir. İstendiği takdirde benzer uygulama aynı esaslarla diğer bölgeler için de gerçekleştirilebilecektir.

Kurumun yönetim kademesiyle yapılan görüşmeler sonucunda, hâlihazırda kurulu sistemin artık ihtiyaca etkin olarak cevap vermediği ve daha maliyet etkin bir sistem arzu edildiği anlaşılmıştır. Atıl kapasitenin azaltılması ve ihtiyaç gösteren yerlerde daha fazla hizmet verilmesi için bazı tesislerin kapatılması planlanmaktadır. Bu ihtiyacın ortaya çıkmasındaki nedenleri şöyle sıralayabiliriz:

- İçcelerden diğer ilçelere veya il merkezine göç sonucunda nüfus oranları önemli ölçüde değişmiştir. Özellikle genç nüfusu az olan ilçelerde 
tesislerin kapatılmasının uygun olabileceği değerlendirilmektedir.

- Ulaşım imkânlarındaki gelişmeler, önceden kolaylıkla gidilemeyen komşu ilçelere ulaşımı zaman ve maliyet açısından mümkün kılmıştır.

- Tesis sayısının azaltılması ile ortaya çıkacak fazla personel, yeteneklerine göre diğer işlerde görevlendirilebilir. Böylelikle kurumun yeni personel intiyaCı dışarıdan personel temin edilmeden karşılanabilir.

- Tesis sayısının azaltılması ile faaliyetine son verilecek binaların diğer kamu kurumlarına tahsis edilerek daha etkin kullanılması ve ülke ekonomisine dolaylı olarak katkı yapılması temin edilebilir.

- Kapatılacak tesisler sayesinde buralara tahsis edilen kaynaklar genel bütçede kalacağından tasarruf edilebilir.

Mevcut durumda, bölgede hizmet veren 24 adet tesis bulunmaktadır. Tablo 1'de bölgedeki mevcut tesislerin ilçeleri ve merkez ilçeleri gösterilmektedir.

Tablo 1: Mevcut Tesisler

\begin{tabular}{|c|c|c|c|c|c|}
\hline $\begin{array}{c}\text { Tesislerin } \\
\text { Bulunduğu } \\
\text { Illçeler }\end{array}$ & $\begin{array}{c}\text { Merkez } \\
\text { Ilçeler }\end{array}$ & $\begin{array}{c}\text { Tesislerin } \\
\text { Bulunduğu } \\
\text { IIçeler }\end{array}$ & $\begin{array}{c}\text { Merkez } \\
\text { ilç̧eler }\end{array}$ & $\begin{array}{c}\text { Tesislerin } \\
\text { Bulunduğu } \\
\text { ilç̧eler }\end{array}$ & $\begin{array}{c}\text { Merkez } \\
\text { Ilçeler }\end{array}$ \\
\hline D1 & $\sqrt{ }$ & D21 & & D40 & \\
\hline D2 & & D22 & $\sqrt{ }$ & D41 & \\
\hline D7 & & D23 & & D42 & $\sqrt{ }$ \\
\hline D8 & & D24 & & D43 & \\
\hline D9 & & D31 & & D49 & \\
\hline D10 & & D32 & $\sqrt{ }$ & D50 & \\
\hline D11 & & D38 & & D51 & \\
\hline D12 & $\sqrt{ }$ & D39 & & D52 & $\sqrt{ }$ \\
\hline
\end{tabular}

Kurumun genel yönetimi, merkez ilçelerdeki tesislerin açık kalmasını istemektedir. Bu nedenle $D_{1}, D_{12}$, $D_{22^{\prime}}, D_{32}, D_{42^{\prime}}$ ve $D_{52}$ kodları ile temsil edilen altı adet il merkezi değerlendirme dışında tutulmuştur. Böylece, problem geri kalan 18 tesisten hangilerinin açık tutulup hangilerinin kapatılması gerektiğine karar verme problemine indirgenmiştir.

Mevcut tesislerin değerlendirilmesi için kurumun genel yönetimi tarafından belirlenen kriterler ve bu kriterlere ilişkin açıklamalar aşağıda sunulmuştur.

$\mathrm{K}_{1}$ ( IIlçe Nüfusu): Illçede ikamet eden ve o tesisten hizmet alacak vatandaşların sayısını göstermektedir. Genel yönetim, nüfus yoğunluğu fazla olan ilçelerdeki tesislerin mümkün olduğunca açık bulundurulmasını istemektedir. Bu kriter için Türkiye İstatistik Kurumu 2012 yılı verilerinden yararlanılmıştır.
$\mathrm{K}_{2}$ (Yıllık Bakım ve İşletme Maliyetleri): Kurum yönetiminden, hâlihazırda bulunan tesislerin yıllık bakım ve işletme maliyetleri temin edilerek, her tesis tipi için yıllık ortalama bakım ve işletme maliyetleri hesaplanmıştır. Bu kriter, sistemde mevcut tesislerin yıllık bakım ve işletme maliyetlerini yansıtmaktadır. Kurum yönetiminin maliyet etkin bir yapı istemesi, ortalama yıllık bakım ve işletme maliyetleri az olan tesislerin mümkün olduğunca açık bulundurulmasını gerektirmektedir.

$\mathrm{K}_{3}$ (il Merkezine Uzaklık): II merkezlerindeki tesislerin açık kalması yönetimin taleplerinden biridir ve bu nedenle, il merkezlerindeki tesislerin açık olması buraya yakın ilçelerdeki tesislerin açık kalma şansını azaltacaktır. Bu kriter, alternatif ilçelerin il merkezlerine olan uzaklıklarını göstermektedir. Genel yönetim, herhangi bir vatandaşa en yakın hizmet merkezinin mümkün olduğunca 90 km'den daha uzakta olmasını istememektedir.

$\mathrm{K}_{4}$ (Illçe Güvenlik Düzeyi): Bu kriter, ilçelerin güvenlik seviyelerini yansıtmaktadır. İlçelerin tamamı yıllık suç oranları, terör eylemleri, izinsiz gösteri, kamu tesislerine yapılan sabotaj, ilçede bulunan polis ve asker sayısı dikkate alınarak yönetim tarafından değerlendirilmiş ve beş güvenlik seviyesine ayrılmıştır. Yeterli güvenlik seviyesine sahip olmayan ilçelerde tesis bulunması arzu edilmemektedir.

$\mathrm{K}_{5}$ (Tesis Bina Durumu): Bu kriter, kurulu tesis binalarının durumlarını göstermektedir. Bina durumuna ilişkin değerlendirmeler kurum yönetimi tarafından binaların yapım yılı, yıpranma seviyesi, alt yapı, Isı yalıtım durumları vb. kriterler dikkate alınarak yapılmıştır. Yönetim, bina durumu iyi olan tesislerin mümkün olduğunca açık kalmasını istemektedir.

$\mathrm{K}_{6}$ (IIlçe Gelişmişlik Düzeyi): Bu kriter, alternatif ilçelerin gelişmişlik düzeylerini yansıtmaktadır. Gelişmişlik düzeyi yüksek olan ilçelerdeki tesislerin mümkün olduğunca açık bulundurulması hedeflenmektedir. İlçelerin gelişmişlik düzeyleri, Kalkınma Bakanlığı tarafından 2004 yılında yapılan bir çalışmaya ait veriler kullanılarak modele yansıtılmıştır. Çalışmadaki gelişmişlik değerleri +6 ile -3 aralığındadır ve çalışmadaki alternatiflerin tamamının değeri negatiftir (Kalkınma Bakanlığı, 2004).

Politik, siyasi ve kamusal bir karar olması nedeniyle karar vericiler, kriterlerin ağırlıkları konusunda kesin bir yargıya varamamışlardır. Ancak, kriterler için önem derecelerine ilişkin olarak bir sıralama yapmışlardır. Kurum yönetimi tarafından yapılan sıralama şu şekildedir: $K 1 \geq K 3 \geq K 5 \geq K 4 \geq K 6 \geq K 2$. Bu çalışmada, kamu kurumu tarafından belirlenen niteliklerden en fazlasına sahip olan tesisleri belirlemek amacıyla 
SMAA-TRI metodu kullanılmıştır. Problemin çözümü için ÇKKV yöntemleri arasından SMAA-TRI metodunun seçilme nedenleri şöyle sıralanabilir:

- Bazı alternatifler için kriter değerleri bilinmemektedir.

- Incelenen problem kamuyu ilgilendiren, politik bir problemdir ve karar verici sayısı birden fazladır.

- Karar vericiler tercihlerini net olarak ifade etmekten kaçınmaktadır. Bu nedenle, alternatiflerin kesin kriter değerlerine ulaşmak mümkün değildir.

- Kriter ağırlıkları kesin olarak bilinmemektedir.
Yönetimden, kriterlerin birbirlerine olan hiyerarşik üstünlükleri dışında herhangi bir bilgi alınamamaktadır.

- Problem bir sınıflandırma yapmayı gerektirmektedir.

Merkez ilçeler çıkıldıktan sonra kalan 18 alternatif tesis belirlenen altı kritere göre değerlendirilmiş ve iki kümeye ayrılmıştır. Birinci küme, açık kalacak tesisler kümesi; ikinci küme, kapatılacak tesisler kümesini oluşturmaktadır. Alternatiflerin kriterlere göre değerlendirmeleri için Tablo 2'de gösterilen veriler kullanılmıştır.

Tablo 2: Alternatifler Değerleri

\begin{tabular}{|c|c|c|c|c|c|c|}
\hline Alternatif & Nüfus & Maliyet & Uzaklık & Güvenlik & Tesis & Gelişmişlik \\
\hline $\mathrm{D}_{2}$ & 26181 & 327 & 61 & 1 & 2 & 1,117 \\
\hline $\mathrm{D}_{7}$ & 30555 & 548 & 45 & 1 & 2 & 0,861 \\
\hline $\mathrm{D}_{8}$ & 18195 & 503 & 59 & 2 & 2 & 1,397 \\
\hline $\mathrm{D}_{9}$ & 62259 & 942 & 69 & 3 & 2 & 0,522 \\
\hline $\mathrm{D}_{10}$ & 19847 & 553 & 57 & 1 & 1 & 1,041 \\
\hline $\mathrm{D}_{11}$ & 28658 & 275 & 64 & 2 & 1 & 1,082 \\
\hline $\mathrm{D}_{21}$ & 77597 & 942 & 22 & 3 & 2 & 0,469 \\
\hline $\mathrm{D}_{23}$ & 37543 & 566 & 66 & 2 & 2 & 0,628 \\
\hline $\mathrm{D}_{24}$ & 31330 & 484 & 60 & 1 & 2 & 0,377 \\
\hline $\mathrm{D}_{31}$ & 23740 & 268 & 32 & 1 & 2 & 0,885 \\
\hline $\mathrm{D}_{38}$ & 43396 & 449 & 50 & 3 & 1 & 1,099 \\
\hline $\mathrm{D}_{39}$ & 35718 & 631 & 93 & 2 & 2 & 0,161 \\
\hline $\mathrm{D}_{40}$ & 61648 & 750 & 96 & 3 & 2 & 0,807 \\
\hline $\mathrm{D}_{41}$ & 27915 & 453 & 45 & 2 & 2 & 0,811 \\
\hline $\mathrm{D}_{43}$ & 67744 & 792 & 93 & 2 & 2 & 0,671 \\
\hline $\mathrm{D}_{49}$ & 38969 & 410 & 50 & 3 & 2 & 0,079 \\
\hline $\mathrm{D}_{50}$ & 19272 & 314 & 77 & 1 & 2 & 1,390 \\
\hline $\mathrm{D}_{51}$ & 32912 & 324 & 81 & 3 & 2 & 0,142 \\
\hline
\end{tabular}

SMAA metodunun gelişmesine önemli katkılarda bulunan Tervonen, JAVA tabanlı bir açık kaynak yazılımını JSMAA adı altında internet üzerinden kullanıma sunmuştur (Tervonen, 2012). JSMAA yazılımı ile SMAA-2 ve SMAA-TRI uygulamaları gerçekleştirilebilmektedir. Bu çalışmada da SMAA-TRI metodu uygulaması için JSMAA yazılımı kullanılmıştır. JSMAA programına veri girişi için örnek olması bakımından alternatif, kriter ve kriter önceliklerini tanımlama ekranı Şekil 1'de, ilçe nüfusuna göre yapılan veri girişi Şekil 2'de gösterilmiştir. 


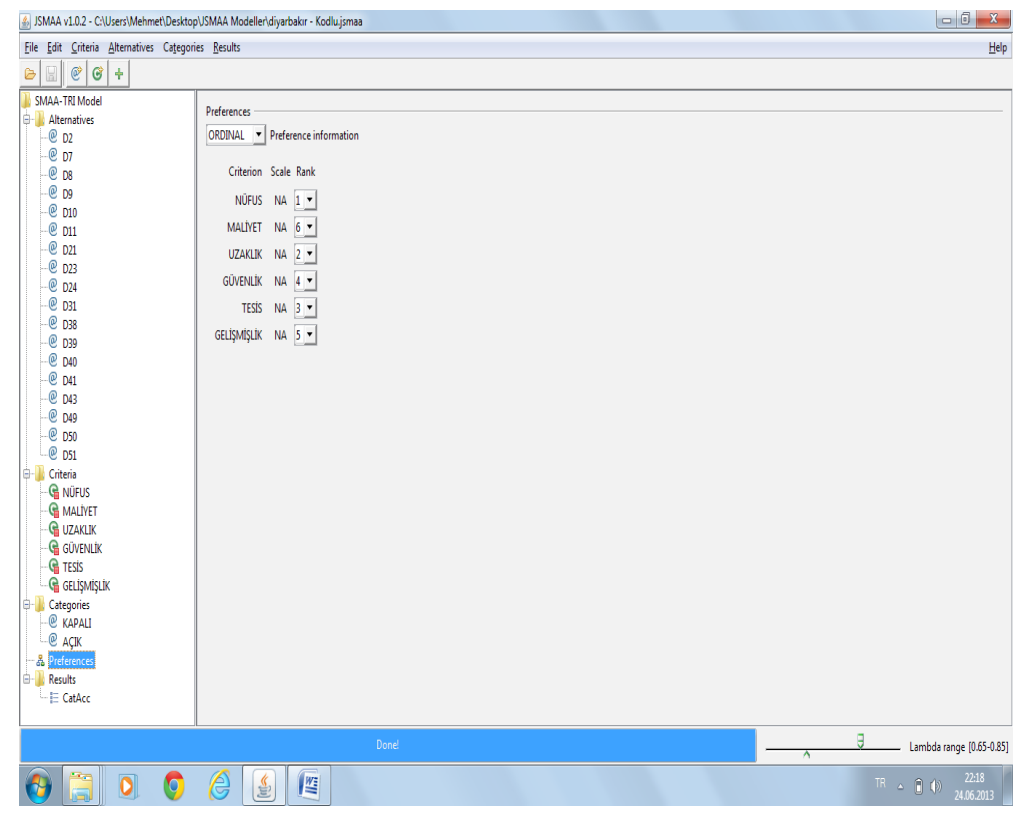

Şekil 1: Alternatif, Kriter Ve Kriter Önceliklerini Tanımlama Ekranı

JSMAA programı, alternatiflerin kriter değerleri ve kriter ağırlık değerleri veya kriter önem sıraları girildikten sonra kategori kabul edilebilirlik indislerini vermektedir. SMAA-TRI modelinin sonucu olarak elde edilen alternatiflerin, kategori kabul edilebilirlik indisleri Şekil 3'te gösterilmektedir. Kategori kabul edilebilirlik indisleri, bir alternatifin o kategoriye ne kadar uyduğunun göstergesidir. Örneğin, $D_{41}$ ilçesindeki tesisin birinci kategori kabul edilebilirlik indis değeri 0.92 'dir. Bu değer, ilçedeki tesisin \%92 oranında ka- patılacak tesisler grubuna girdiğini göstermektedir. Karar, bazı ilçeler için \%100'e yakın bir indis değeri ile verilirken $D_{2}$ ve $D_{11}$ gibi ilçeler için $\% 50$ - $\% 60$ aralığında bir indis değeri ile verilmiştir. Yapılan değerlendirmelerde gelecekte oluşabilecek bir değişiklik bu ilçeler için verilen kararları değiştirebilir. Kararın uygulamasına geçilmeden önce maliyet etkinliği dikkate alınarak veriler güncellenebilir ve model tekrar çözümlenebilir.

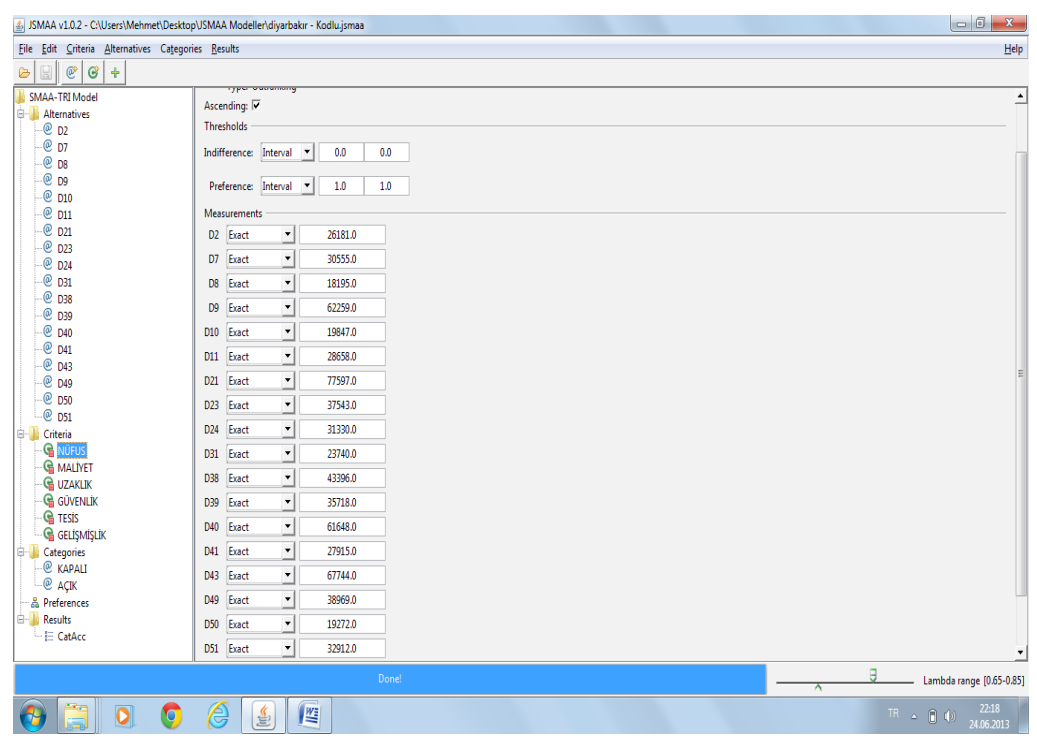

Şekil 2: Programa Veri Girişi 


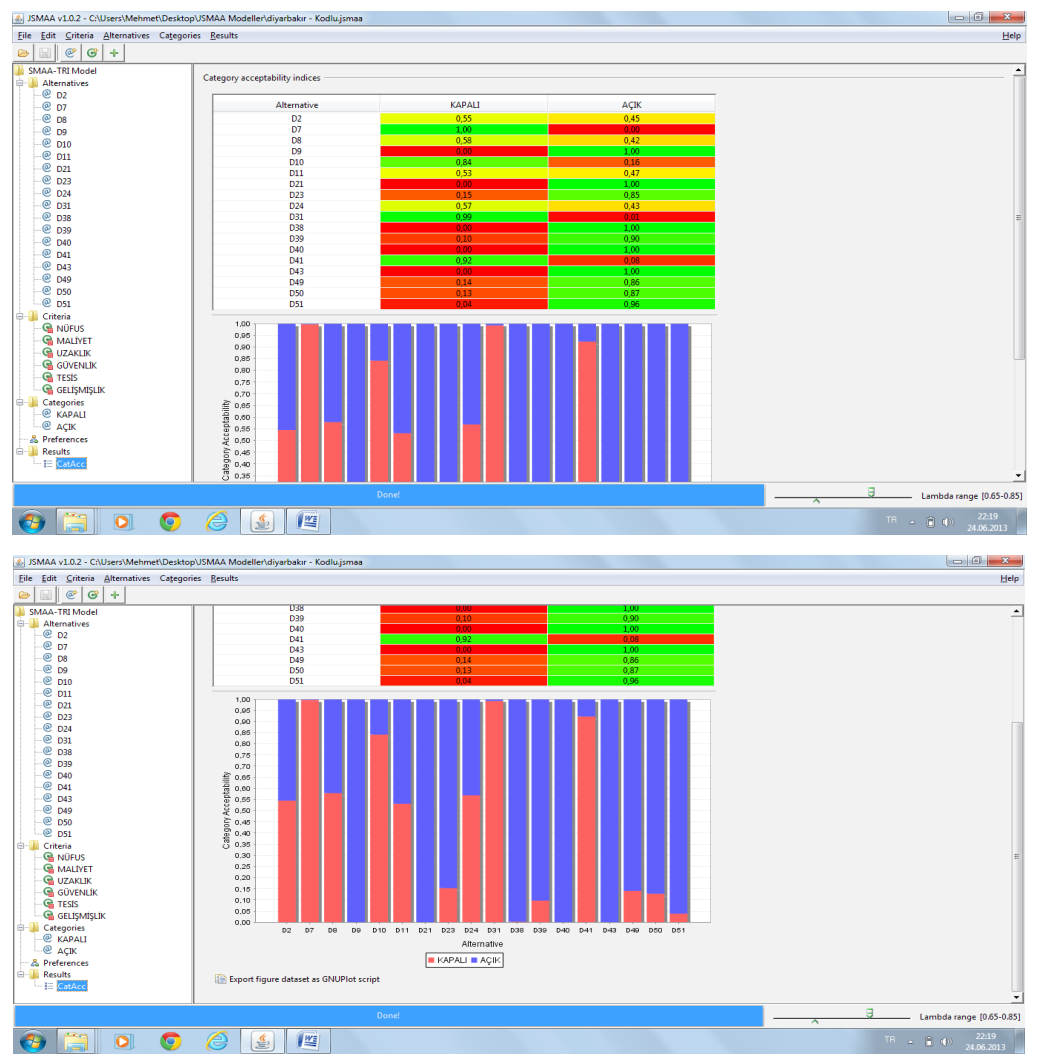

Şekil 3: Kategori Kabul Edilebilirlik Indisleri

Çalışmadaki modeldeiki kategoribulunduğundan, ilçelerdeki tesisler en fazla hangi kategoride bulunma olasılığı fazla ise o grubun üyesi sayılmıştır. SMAATRI metodu, bölgedeki açık olan tesislerden sekiz tanesinin kapatılmasını öngörmüştür. $\mathrm{Bu}$ tesisler Şekil 3'te görüldüğü gibi $\mathrm{D}_{2^{\prime}}, \mathrm{D}_{7^{\prime}}, \mathrm{D}_{8^{\prime}}, \mathrm{D}_{10^{\prime}} \mathrm{D}_{11^{\prime}}, \mathrm{D}_{24^{\prime}} \mathrm{D}_{31^{\prime}}$ ve $\mathrm{D}_{41}{ }^{\prime}$ dir.

\section{SONUÇLAR VE TARTIŞMA}

Bu çalışmada, bir kamu kurumuna ait gerçek bir tesis yeri seçimi problemi ele alınmıştır. Bu problem, temel olarak kamu kurumunun ülke çapında çeşitli il ve ilçelerde konuşlu hizmet merkezi sayısını azaltmak istemesinden kaynaklanmaktadır. Bu problemin çözümü için mevcut tesisler arasında, kamu kurumunun sahip olmasını istediği niteliklerden en fazlasına sahip olanlar SMAA-TRI metodu ile tespit edilmiştir. Bu yöntem ile bölgedeki mevcut tesislerden merkez ilçelerde bulunan 6 tanesi hariç tutularak kalan 18 adet hizmet birimi genel yönetim tarafından belirlenen altı kritere göre değerlendirilmiştir. Yapılan sınıflandırma ile mevcut hizmet birimleri kapatılması gereken ve açık bulundurulması gereken tesisler şeklinde iki kategoriye ayrılmıştır. Elde edilen sonuçlar, bölgedeki 8 tesisin kapatılmasını önermektedir.
Tesis yeri seçimi uygun olmayan yerleşmelerin düzeltilmesindeki yüksek maliyet, hızlı değişim, ileri teknoloji, zaman kısıtlamaları nedenleriyle günümüzde çok önemli bir araştırma konusu olma özelliğini korumaktadır. Bu konu özellikle kamu kurumlarında politik ve siyasi nedenlerle zor kararlar alınması ile daha karmaşık bir hal almaktadır. Süreçte bulunan birçok belirsizlik geleneksel yöntemlerle hatasız bir karar vermeyi imkânsız hale getirmektedir.

Yöneticiler, kurumlarda verilecek kararlar üzerinde büyük ölçüde söz sahibi olmak isterler. Özel kurumlarda yöneticiler, tercihlerini açıkça dile getirerek ortaya koyabilirler. Ama kamu kurumlarında alınacak kararların siyasi ve politik nitelikleri ve kamuoyunda yaratacağı etki düşünülerek özel sektör kadar rahat davranılamaz. İşte SMAA metodu bu durumlar için geliştirilmiş̧ir. Yöneticiye alternatifler arasından en iyisini sunmak yerine, hangi alternatiflerin ne oranda seçilebilir olduğu bilgisini verir. SMAA bu özelliği nedeniyle özellikle kamu sektörü için uygun bir ÇKKV metodudur. 


\section{KAYNAKLAR}

Badri, M.A. (1999) "Combining the Analytic Hierarchy Process and Goal Programming for Global Facility Location Allocation Problem" International Journal of Production Economics, 62(3):237-248.

Blin, J.M. (1974) "Fuzzy Relations in Group Decision Theory" Journal of Cybernetics, 4:17-22.

Chou, T.Y., Hsu, C.L. ve Chen, M.C. (2008) "A fuzzy Multicriteria Decision Model for International Tourist Hotels Location Selection" International Journal of Hospitality Management, 27:293-301.

Farahani, R.Z., Steadie, Seifi M. ve Asgari, N. (2010) "Multiple Criteria Facility Location Problems: A Survey" Applied Mathematical Modelling, 34:1689-1709.

Figueira, J., Greco, S. ve Ehrgott, M. (Eds.) (2005) Multiple Criteria Decision Analysis: State of the Art Surveys, New York, Springer Science\&Business Media, Inc.

Güneri, A.F., Cengiz, M. ve Şeker, S. (2009) "A fuzzy ANP Approach for Shipyard Location Selection" Expert Systems with Applications, 36:7992-7999.

Hokkanen, J., Lahdelma, R., Miettinen, K. ve Salminen, P. (1998) "Determining the Implementation Order of a General Plan by Using a Multicriteria Method" Journal of Multi-Criteria Decision Analysis, 7(5):273-284.

Hokkanen, J., Lahdelma, R. ve Salminen, P. (1999) "A Multiple Criteria Decision Model for Analyzing and Choosing Among Different Development Patterns for the Helsinki Cargo Harbor" Socio-Economic Planning Sciences, 33:1-23.

Ishizaka, A., Nemery, P. ve Lidouh, K. (2013) "Location Selection for the Construction of a Casino in the Greater London Region: A Triple Multi-Criteria Approach" Tourism Management, 34:211-220.

Kahraman, C., Ruan, D. ve Doğan, İ. (2003) "Fuzzy Group Decision-Making for Facility Location Selection" Information Sciences, 157:135 -153.

Kalkınma Bakanlığı (2004) http://ekutup.dpt.gov.tr/ bolgesel/gosterge/2004/ilce.pdf, (21.07.2013)

Lahdelma, R. ve Salminen, P. (2001) "SMAA-2: Stochastic Multicriteria Acceptability Analysis for Group Decision Making" Operations Research, 49(3):444-454.
Lahdelma, R., Salminen, P. ve Hokkanen, J. (2002) "Locating a Waste Treatment Facility by Using Stochastic Multicriteria Acceptability Analysis with Ordinal Criteria" European Journal of Operational Research, 142(2):345356.

Lahdelma, R., Miettinen, K. ve Salminen, P. (2003) "Ordinal Criteria in Stochastic Multicriteria Acceptability Analysis (SMAA)" European Journal of Operational Research,147(1):117-127.

Lahdelma, R., Miettinen, K. ve Salminen, P. (2005) "Reference Point Approach for Multiple Decision Makers" European Journal of Operational Research, 164(3):785-791.

Menou, A., Benallou, A., Lahdelma, R. ve Salminen, P. (2010) "Decision Support for Centralizing Cargo at a Moroccan Airport Hub Using Stochastic Multicriteria Acceptability Analysis" European Journal of Operational Research, 204:624-629.

Tervonen, T. ve Figueira, J. (2008) "A Survey on Stochastic Multicriteria Acceptability Analysis Methods" Journal of Multi-Criteria Decision Analysis, 15:1-14.

Tervonen, T., Lahdelma, R., Dias, J.A., Figueira J. ve Salminen P. (2009) "SMAA-TRI: A Parameter Stability Analysis Method for ELECTRE-TRI" Kiker, G.A. ve Linkov, I. (eds.) Environmental Security in Harbors and Coastal Areas, Berlin, Springer.

Tervonen, T. (2012) "JSMAA: Open Source Software for SMAA Computations" International Journal of Systems Science, 1-13.

Tervonen, T. ve Lahdelma, R. (2007) "Implementing Stochastic Multicriteria Acceptability Analysis" European Journal of Operational Research, 178(2):500-513.

Vahidnia, M.H., Alesheikh, A.A. ve Alimohammadi, A. (2009) "Hospital Site Selection Using Fuzzy AHP and its Derivatives" Journal of Environmental Management, 90(10):3048-3056.

Yu, W. (1992) "Aide Multicritère à la Décision Dans le Cadre de la Problématique du tri: Concepts, Méthodes Et Applications" Yayınlanmamış Doktora Tezi, Paris, Université Paris-Dauphine. 
